\title{
Strategi Corporate Social Responsibility dalam Pembentukan Citra Perusahaan (Studi pada Kegiatan CSR di PT. Wijaya Karya)
}

\author{
Dela Melinda Savila, Lusia Savitri Setyo Utami \\ saviladela24@gmail.com,lusias@fikom.untar.ac.id \\ Fakultas Ilmu Komunikasi Universitas Tarumanagara
}

\begin{abstract}
The company has close links with public. As a form of responsibility, companies need to carry out Corporate Social Responsibility activities. The purpose of this research is to know the strategy of the Corporate Social Responsibility program conducted by Public Relations at PT. Wijaya Karya in forming corporate image. This research is conducted by qualitative with the case study research method. This research is conducted using Public Relations, Corporate Social Responsibility strategies, and corporate image theory. Based on the interviews, the strategy of the Corporate Social Responsibility program conducted by PT. Wijaya Karya are 4 Pilar WIKA consisting of WIKA hijau, WIKA pintar, WIKA peduli, and WIKA sehat. From the research that has been done, the Corporate Social Responsibility program conducted by PT. Wijaya Karya has a role in forming a positive company image because the activities carried out are very beneficial and sustainable. In addition, the communication between the company and public is very good in Corporate Social Responsibility activities so people gave a positive response to the project carried out by PT. Wijaya Karya.
\end{abstract}

Keywords: corporate social responsibility strategy, image, Public Relations.

\begin{abstract}
Abstrak
Perusahaan memiliki kaitan yang erat dengan masyarakat. Sebagai bentuk tanggung jawab kepada masyarakat, perusahaan perlu melakukan kegiatan Corporate Social Responsibility. Penelitian ini bertujuan untuk mengetahui strategi program Corporate Social Responsibility yang dilakukan Public Relations di PT. Wijaya Karya dalam membentuk citra perusahaan. Pendekatan yang digunakan dalam penelitian ini adalah kualitatif dengan metode penelitian studi kasus. Teori yang digunakan dalam penelitian ini adalah Public Relations, strategi Corporate Social Responsibility, dan citra perusahaan. Berdasarkan hasil wawancara, strategi program Corporate Social Responsibility yang dilakukan PT. Wijaya Karya terdiri dari 4 pilar WIKA yaitu WIKA hijau, WIKA pintar, WIKA peduli, dan WIKA sehat. Secara keseluruhan program Corporate Social Responsibility yang dilakukan PT. Wijaya Karya berperan dalam pembentukan citra perusahan yang positif karena kegiatan yang dilakukan sangat bermanfaat dan berkelanjutan. Selain itu, komunikasi yang terjalin antara perusahaan dan masyarakat sangat baik dalam kegiatan Corporate Social Responsibility sehingga masyarakat memberikan respon yang positif terhadap proyek yang dilakukan oleh PT. Wijaya Karya.
\end{abstract}

Kata Kunci: citra, public relations, strategi Corporate Social Responsibility.

\section{Pendahuluan}

Perusahaan memiliki kaitan yang erat dengan masyarakat. Untuk menjaga kaitan tersebut, perusahaan harus menjalin hubungan yang baik dengan publiknya karena pendapat publik akan mempengaruhi hal atau kegiatan yang dikerjakan 
perusahaan. Perusahaan memiliki peran yang besar untuk mengubah dan membentuk perilaku masyarakat untuk kepentingan bersama. Oleh karena itu dalam sebuah perusahaan dibutuhkan Public Relations. Tugas seorang Public Relations yaitu untuk mengubah sikap publik sesuai dengan yang diinginkan. Oleh karena itu, Public Relations harus mementingkan keinginan publik untuk menjaga komunikasi yang baik antara perusahaan dan publiknya. Aspek tersebut membuat perusahaan harus menyesuaikan diri dengan lingkungan sekitar dan mempertahankan hubungan yang baik dengan stakeholder sehingga perusahaan harus melakukan Corporate Social Responsibility (CSR) untuk mengembalikan rasionalisasi moralitas mereka pada praktek-praktek yang bersifat etis dan harus memastikan bahwa Corporate Social Responsibility yang mereka lakukan sesuai dengan tuntutan yang dibuat oleh para praktisi Public Relations yang merupakan ethical guardian dalam organisasi.

Di Indonesia, konsep Corporate Social Responsibility diwajibkan dan sudah diatur oleh undang-undang sebagai suatu kewajiban hukum yang harus dipatuhi organisasi atau perusahaan yang biasa dikenal dengan sebutan TJSL. Akan tetapi, penulis melihat banyak perusahaan yang masih belum menerapkan CSR dengan benar. Masih banyak perusahaan yang mengabaikan dan belum melihat manfaat CSR yang sesungguhnya.

Bisnis yang paling rentan terhadap isu sosial dan lingkungan adalah bisnis yang bergerak di bidang industri dan konstruksi. Di Indonesia, bisnis yang bergerak dibidang tersebut kebanyakan dimiliki oleh Badan Usaha Milik Negara (BUMN). Jika perusahaan tidak berhasil mengambil tindakan untuk menjaga hubungan dengan publik, maka kemungkinan akan terjadi konflik antara perusahaan dan masyarakat. Selain itu, penulis juga melihat penelitian terdahulu yang melakukan penelitian mengenai Corporate Social Responsibility bagi reputasi perusahaan dengan judul Membangun Reputasi Perusahaan Melalui Program CSR (Studi Pada Program CSR Sinar Mas Land Di RTH/RPTRA Kalijodo) yang diteliti oleh Dewi Suryani Putri, dan Yugih Setyanto, hanya membahas sebatas aktivitas dan pengaruh Corporate Social Responsibility terhadap citra perusahaan tanpa mengetahui strategi Corporate Social Responsibility untuk membangun citra perusahaan yang positif dan kendala dari kegiatan Corporate Social Responsibility yang dihadapi. Hal ini membuat penulis tertarik untuk melihat lebih jauh strategi dan komunikasi Corporate Social Responsibility yang dilakukan oleh salah satu perusahaan BUMN. Teori yang digunakan dalam penelitian ini yaitu Public Relations, strategi Corporate Social Responsibility, dan citra.

Salah satu perusahaan yang terkenal dengan program Corporate Social Responsibility adalah PT. Wijaya Karya (WIKA). Meskipun merupakan perusahaan BUMN, PT. Wijaya Karya memiliki reputasi yang baik di mata publik. Selain itu, kegiatan Corporate Social Responsibility yang dilakukan sangat beragam. Banyaknya perluasan divisi yang dilakukan, membuat perusahaan ini memiliki strategi dalam menjalankan program Corporate Social Responsibility. Dengan menjalankan kegiatan Corporate Social Responsibility yang sesuai, tepat sasaran, dan berkelanjutan, maka kan berdampak bagi kinerja dan kesejahteraan organisasi itu sendiri. Penerapan program Corporate Social Responsibility yang dilakukan secara konsisten akan membentuk citra perusahaan dan jika dilakukan secara berkala akan terbentuk citra yang positif. Dengan adanya Corporate Social Responsibility, image atau citra perusahaan akan baik di mata masyarakat maupun publik. 
Dela Melinda Savila, Lusia Savitri Setyo Utami: Strategi Corporate Social Responsibility dalam Pembentukan Citra Perusahaan (Studi pada Kegiatan CSR di PT. Wijaya Karya)

\section{Metode Penelitian}

Penulis menggunakan pendekatan kualitatif dalam penelitian ini. Menurut Saryono (2010) penelitian kualitatif adalah penelitian untuk memaparkan sebuah penelitian tanpa dibatasi oleh angka atau statistik. Metode penelitian yang digunakan dalam penelitian ini adalah studi kasus. Menurut Kriyantono (2009:65) studi kasus adalah metode dengan memakai bermacam-macam data yang bisa dipakai untuk memaparkan dan mendeskripsikan dari berbagai aspek peristiwa secara sistem, organisasi, dan individu dengan komprehensif. Penulis menggunakan metode pengumpulan data berupa wawancara mendalam, observasi tidak langsung, dan dokumentasi. Subjek dalam penelitian ini yaitu Direktur utama PT. Wijaya Karya Industri \& Konstruksi, Public Relations PT. Wijaya Karya Industri \& Konstruksi, Project Manager PT. Wijaya Karya Industri \& Konstruksi, Staff DPR RI Komisi IV, dan warga yang tinggal di sekitar PT. wijaya Karya. Objek pada penelitian ini yaitu strategi Corporate Social Responsibility dalam pembentukam citra. Teknik pengolahan data yang digunakan adalah pengumpulan data, reduksi data, penyajian data, dan penarikan kesimpulan. Teknik keabsahan data yang digunakan yaitu triangulasi data.

\section{Hasil Penemuan dan Diskusi}

\section{Public Relations PT. Wijaya Karya}

Setiap perusahaan terutama perusahaan besar pasti memiliki Public Relations atau humas. Tugas Public Relations dalam setiap perusahaan berbeda-beda. Menurut Cutlip \& Center (2011) menyatakan ada tahapan atau yang melatarbelakangi pelaksanaan program Public Relations:

a. Fact Finding yaitu mendefinisikan masalah untuk menganalisa opini publik terhadap organisasi atau perusahaan. Dalam menjalankan tugasnya, Public Relations PT. Wijaya Karya terbagi menjadi tim. Tim yang melakukan fact finding adalah tim survei.

b. Planning yaitu merancang strategi sesuai dengan analisa yang dilakukan dan mengambil keputusan berdasarkan kepentingan publik. PT. Wijaya Karya memiliki tim yang akan merancang kegiatan acara seperti kegiatan Corporate Social Responsibility yang akan dilakukan oleh tim Corporate Social Responsibility.

c. Communicating yaitu mengkomunikasikan implementask dan hasil kegiatan agar dapat mempengaruhi opini publik. PT. Wijaya Karya memiliki tim yang akan mengkomunikasikan setiap kegiatan atau acara yang dilakukan. Tim yang bertugas adalah tim publikasi dan tim digital media.

d. Evaluating yaitu tahap untuk menilai hasil-hasil kegiatan program dari perencanaan hingga hasil evaluasi. Dalam hal ini, Public Relations PT. Wijaya Karya akan melakukan evaluasi untuk setiap kegiatan yang dilakukan terutama kegiatan Corporate Social Responsibility.

Public Relations di PT. Wijaya Karya disebut Sekretariat Perusahaan yang dibagi ke dalam bentuk tim yaitu tim survei yang melakukan fact finding, tim Corporate Social Responsibility yang membuat planning kegiatan seperti Corporate Social Responsibility, dan tim publikasi yang akan mengkomunikasikan kegiatan yang dilakukan PT. Wijaya Karya. 


\section{Strategi Corporate Social Responsibility PT. Wijaya Karya}

Sebelum melakukan kegiatan Corporate Social Responsibility, perusahaan memiliki strategi tersendiri seperti halnya yang dijelaskan oleh Kartini, D (2009:47) dalam implementasi Corporate Social Responsibility dibutuhkan strategi khusus sehingga berjalan sesuai dengan gagasan yang sudaj ditentukan. PT. Wijaya Karya memiliki banyak anak perusahaan sehingga membuat PT. Wijaya Karya mempunyai strategi tersendiri dalam menjalankan kegiatan Corporate Social Responsibility yaitu dengan adanya unsur 4 pilar WIKA yaitu WIKA hijau, WIKA peduli, WIKA sehat, dan WIKA pintar. Hal ini juga sesuai dengan teori dari Kartini, D (2009:47) dalam implementasi Corporate Social Responsibility dibutuhkan strategi ekstra yang terdiri dari beberapa agenda yaitu:

1. Guildelines dan kode etik.

PT. Wijaya Karya memiliki pedoman dan berfokus pada Good Corporate Governance sehingga kegiatan Corporate Social Responsibility yang dilakukan sesuai dengan tata etika dari Kementerian BUMN.

2. Sistem dan kebijakan manajemen korporat

Sistem dan kebijakan Korporat yang dilakukan PT. Wijaya Karya merupakan pembaharuan ide dari Kementerian BUMN. PT. Wijaya Karya mengembangkan kegiatan Corporate Social Responsibility yang diberikan pemerintah yaitu mengenai penghijauan.

3. Strategi kepemimpinan korporat dalam Corporate Social Responsibility Berawal dari ide pemerintah untuk menanggulangi bencana dan kepedulian terhadap lingkungan, membuat PT. Wijaya Karya memiliki strategi dalam menjalankan Corporate Social Responsibility yaitu 4 pilar WIKA yaitu WIKA hijau yang melakukan kegiatan Corporate Social Responsibility tentang penghijauan, WIKA pintar yang melakukan kegiatan Corporate Social Responsibility untuk mengajar dan memberikan edukasi untuk masyarakat, WIKA peduli yang berfokus pada kegiatan Corporate Social Responsibility untuk membantu masyarakat yang terkena bencana alam, dan WIKA sehat yaitu kegiatan Corporate Social Responsibility yang peduli terhadap kesehatan dan lingkungan.

4. Komitmen dan kemitraan di antara stakeholders

Dalam hal ini, PT. Wijaya Karya berkomitmen untuk melakukan kegiatan Corporate Social Responsibility yang bersifat jangka Panjang untuk menjaga hubungan dengan stakeholders atau publik sehingga saat melakukan kegiatan evaluasi, PT. Wijaya Karya dapat membuat evaluasi yang sesuai dan tepat karena kegiatan yang dilakukan dipantau secara berkelanjutan.

\section{Implementasi Kegiatan Corporate Social Responsibility}

Corporate Social Responsibility adalah upaya perusahaan untuk memenuhi peraturan pemerintah dan sebagai rasa peduli kepada masyarakat. Menurut Frynas (2009) alasan perusahaan melaksanakan kegiatan Corporate Social Responsibility yaitu:

1) Untuk memenuhi hukum.

PT. Wijaya Karya melakukan kegiatan Corporate Social Responsibility karena perusahaan BUMN diwajibkan untuk melakukan kegiatan Corporate Social Responsibility dan memenuhi aturan yang sudah dibuat oleh pemerintah. 
Dela Melinda Savila, Lusia Savitri Setyo Utami: Strategi Corporate Social Responsibility dalam Pembentukan Citra Perusahaan (Studi pada Kegiatan CSR di PT. Wijaya Karya)

2) Untuk mendapatkan image yang positif.

Corporate Social Responsibility yang dilakukan PT. Wijaya Karya membuat perusahaan memiliki citra yang baik dan dinilai baik oleh masyarakat.

3) Untuk mendapatkan izin dari masyarakat sekitar.

Salah satu alasan Corporate Social Responsibility yang dilakukan oleh PT. Wijaya Karya yaitu untuk keberlangsungan pabrik yang didirikan sehingga dapat bertahan lama dan agar menerima respon yang baik dari masyarakat yang tinggal di daerah pabrik tersebut.

4) Untuk menekan atau menahan isu sosial.

Kegiatan Corporate Social Responsibility yang dilakukan oleh PT. Wijaya Karya dapat membuat perusahaan memperoleh tanggapan yang baik dari masyarakat sehingga pabrik atau proyek yang sedang dikerjakan tidak menimbulkan masalah atau konflik sosial dengan masyarakat sekitar.

Corporate Social Responsibility adalah suatu cara bagi perusahaan yang dilakukan untuk memenuhi peraturan perundang-undangan, bagian dari risk management, dan strategi perusahaan dalam pembentukan citra yang baik di mata publik. Selain itu, Corporate Social Responsibility juga dapat menolong perusahaan untuk tetap menjalankan bisnis atau usahanya dengan mendapat dukungan dari masyarakat setempat sehingga usaha yang dilakukan perusahaan dapat berjalan dengan lancar dan jangka panjang.

\section{Corporate Social Responsibility Dalam Pembentukan Citra Yang Positif}

Program Corporate Social Responsibility yang sesuai dan berkelanjutan akan memberikan hasil yang baik, contohnya seperti reputasi atau citra yang baik bagi perusahaan. Citra yang terbentuk merupakan hasil dari berbagai usaha yang dilakukan perusahaan. Seperti yang dijelaskan oleh Burke (2011:8-9) mengidentifikasi elemen dalam membangun citra perusahaan yang menguntungkan (positif) yaitu:

1. Responsibility atau tanggung jawab. Salah satu hal yang dilakukan PT. Wijaya Karya dalam membangun citra yang positif yaitu dengan melakukan kegiatan Corporate Social Responsibility. Corporate Social responsibility merupakan salah satu elemen dalam pembentukan citra yang positif.

2. Communication (komunikasi) ditandai dengan adanya transparansi dan komunikasi dilakukan secara terbuka. Bentuk komunikasi yang dilakukan oleh PT. Wijaya Karya yaitu komunikasi yang mengikutsertakan masyarakat untuk ikut terlibat dalam kegiatan yang dilakukan seperti kegiatan Corporate Social Responsibility. Dalam hal ini, masyarakat bisa menyampaikan aspirasi atau keinginannya dan perusahaan akan melakukan dialog atau musyawarah dengan masyarakat.

3. Leadership (kepemimpinan) merupakan bentuk kepemimpinan yang baik dan solid. Kepemimpinan dalam kegiatan Corporate Social Responsibility PT. Wijaya Karya dilakukan oleh Sekretariat Perusahaan atau yang biasa disebut Public Relations. Sekretariat Perusahaan PT. Wijaya Karya bagian pusat perusahaan akan melakukan koordinasi dengan seluruh anak perusahaan dan divisi untuk kegiatan Corporate Social Responsibility dan semua kegiatan humas lainnya. 
Corporate Social Responsibility memiliki pengaruh yang kuat dalam pembentukan citra yang positif. Kegiatan Corporate Social Responsibility yang dibuat oleh PT. Wijaya Karya memiliki banyak manfaat sehingga membuat publik memberikan tanggapan yang baik untuk perusahaan. Kemauan baik melalui kegiatan Corporate Social Responsibility yang diberikan PT. Wijaya Karya kepada publik sangat bagus sehingga respon masyarakat sesuai dengan yang diharapkan dan citra positif dapat dipertahankan oleh perusahaan.

\section{Simpulan}

Public Relations di PT. Wijaya Karya memiliki peran yang penting dalam menjalankan program Corporate Social Responsibility, mulai dari melakukan survey, merancang, hingga melakukan publikasi hasil Corporate Social Responsibility. Strategi program Corporate Social Responsibility yang dilakukan PT. Wijaya Karya terdiri dari 4 pilar WIKA yaitu WIKA hijau, WIKA, WIKA peduli, dan WIKA sehat. Implementasi Corporate Social Responsibility PT. Wijaya Karya berdampak positif dan juga efektif dalam pembentukan citra yang positif. Hal ini terlihat dari tanggapan yang diberikan oleh masyarakat terhadap kegiatan Corporate Social Responsibility yang dilakukan PT. Wijaya Karya. Hal tersebut membuktikan bahwa komunikasi eksternal yang diterapkan oleh PT. Wijaya Karya mempengaruhi hubungan dengan masyarakat sehingga menimbulkan respon dan dukungan yang positif dari masyarakat terhadap proyek dan kegiatan yang dilakukan PT. Wijaya Karya. Secara keseluruhan program Corporate Social Responsibility yang dilakukan PT. Wijaya Karya berperan dalam pembentukan citra perusahan yang positif karena kegiatan yang dilakukan sangat bermanfaat dan berkelanjutan. Selain itu, komunikasi yang terjalin antara perusahaan dan masyarakat sangat baik dalam kegiatan Corporate Social Responsibility sehingga masyarakat memberikan respon yang positif terhadap proyek yang dilakukan oleh PT. Wijaya Karya.

Publikasi kegiatan Corporate Social Responsibility di website PT. Wijaya Karya sangat aktif dan baik, tetapi kegiatan yang dipublikasi tidak menampilkan foto-foto hasil Corporate Social Responsibility tersebut. Oleh karena itu, rekomendasi penulis sebaiknya menambahkan foto kegiatan Corporate Social hasil publikasi lebih maksimal dan hendaknya kegiatan Corporate Social yang telah dilakukan PT. Wijaya Karya dijadikan pedoman dan tolak ukur dalam setiap kegiatan usaha atau proyek yang dilakukan. Untuk penelitian selanjutnya, penulis berharap agar lebih mendalami manfaat Corporate Social dan membahas mengenai tantangan Corporate Social Responsibility karena dalam penelitian ini terdapat beberapa kendala dalam kegiatan Corporate Social Responsibility. Selain itu penulis juga berharap agar penelitian ini bisa menjadi pedoman untuk penelitian selanjutnya.

\section{Ucapan Terima Kasih}

Penulis ingin mengucapkan rasa terima kasih yang sebesar-besarnya kepada seluruh pihak yang sudah terlibat dan ikut membantu berjalannya hasil penelitian ini sampai dengan selesai. Peneliti juga ingin mengucapkan terima kasih kepada PT. Wijaya Karya yang sudah bersedia menjadi objek dalam penelitian penulis dan juga kepada semua narasumber pada penelitian ini. 
Dela Melinda Savila, Lusia Savitri Setyo Utami: Strategi Corporate Social Responsibility dalam Pembentukan Citra Perusahaan (Studi pada Kegiatan CSR di PT. Wijaya Karya)

\section{Daftar Pustaka}

Cutlip, Scoot M., Allen H. Center., \& Glen M. Broom. (2011). Effective Public Relations (ed. 9). Jakarta: Kencana

Frynas, Jedrzej George. (2009). Beyond Corporate Social Responsibility : Oil Multinationals And Social Challenges. New York : Cambridge University Press

Kartini, Dwi. (2009). Corporate Social Responsibility Transformasi Konsep Sustainability Management Dan Implementasi Di Indonesia. Bandung: PT Refika Aditama

Kriyantono, Rachmat. (2009). Teknik Praktis Riset Komunikasi. Malang: Prenada Media Group

Putri, Dewi Suryani., \& Setyanto, Yugih. (2017). Membangun Reputasi Perusahaan Melalui Program CSR (Studi Pada Program CSR Sinar Mas Land Di RTH/RPTRA Kalijodo). Prologia, 1 (2). Januari 13, 2020. Terarsip di: http://journal.untar.ac.id/index.php/prologia/index

Saryono. (2010). Metode Penelitian Kualitatif. Bandung : PT. Alfabeta

Underwood, R. L., Klein, N. M., \& Burke, R. R. (2011). Packaging Communication: attentional effects of product imagery. Journal of Product \& Brand Management, 10 (7), 403-422

Untung, Budi. (2014). CSR Dalam Dunia Bisnis.Yogyakarta: CV Andi Offset 